\title{
Comparative Analysis of Vaccines and Probiotics in Fighting the Covid19
}

\author{
Goran Belojevic* \\ Faculty of Medicine, Institute of Hygiene and Medical Ecology, University of Belgrade, Serbia \\ *Corresponding author: Goran Belojevic, Faculty of Medicine, Institute of Hygiene and Medical Ecology, University of \\ Belgrade, Serbia
}

\section{ARTICLE INFO}

Received: 慧 January 27, 2021

Published: 蔧 February 18, 2021

Citation: Goran Belojevic. Comparative Analysis of Vaccines and Probiotics in Fighting the Covid19. Biomed J Sci \& Tech Res 34(1)-2021. BJSTR. MS.ID.005487.

\begin{abstract}
The COVID19 is an unprecedented pandemic that is making a tremendous death toll from the mankind. There are two strategies in stopping the COVID19 pandemic: artificial, with vaccines and natural, with probiotics. Although a vaccine strategy dominates at the moment, this comparative analysis shows some advantages of the probiotic strategy: full availability, rare side effects, low price, application per os, sterilizing immunity, just a few contraindications and storage at room temperatures. Near future will show which of these two strategies is more successful.
\end{abstract}

Keywords: COVID19; Corona Virus; Pandemic; Vaccines; Probiotics

\section{Introduction}

The COVID19 is an unprecedented pandemic that started in the Chinese region of Wuhan in December 2019 [1]. Currently, the COVID19 pandemic has taken around 1.9 million lives [2]. It is hard to predict the duration of this pandemic. However, based on the experiences from the Spanish Flu pandemic, the COVID19 pandemic may last until the end of 2021 [3]. There are two major strategic approaches in fighting the COVID19 pandemic.

A dominating anti-COVID19 strategy is raising the specific immunity with vaccination. Currently, there are three vaccines approved by the Food and Drugs Administration and The European Medicines Agency [4-6]. The vaccination is being performed worldwide, with an expectation of a high response rate and a fast immunization of the world population. Given that currently there are more than 230 vaccines in the process of developing, we may expect tens of approved vaccines in the near future [7]. Another approach in fighting the COVID19 pandemic, supported by a small group of scientific teams, is related to probiotics, with the aim of raising unspecific immunity [8-11]. A program of a massive antiCOVID19 prevention and treatment with probiotics has been proposed $[9,10]$. The aim of this paper is to perform an analytical comparison of the two current strategies in fighting COVID19 pandemic - vaccination and probiotic protection.

\section{Material and Methods}

Vaccination and probiotic protection are compared using the following parameters: origin, availability, side effects, price, infectiveness, contraindications, treatment of the COVID19, aluminium adjuvants and storage. The search of PubMed was performed using the following keywords: "COVID19", "coronavirus", "vaccines" and "probiotics".

\section{Results}

A comparative analysis of the vaccination and the probiotic protection as anti-COVID19 strategies is presented in Table 1. The vaccines $v s$. probiotics comparison shows the following differences, respectively: artificial vs natural method; limited availability for the world population $v s$. the full availability; numerous side effects $v s$. a few side effects; relatively high price $v s$. relatively low price; non-sterilizing immunity vs. sterilizing immunity; numerous contraindications $v s$. few contraindications; not usable for treatment of COVID19 vs. usable for treatment of COVID19 and storage at low and very low temperatures vs. storage at room temperatures. 
Table 1: Comparative analysis of vaccination and probiotics as anti-COVID19 public health procedures.

\begin{tabular}{|c|c|c|c|}
\hline Parameter & Vaccines & Probiotics & References \\
\hline Origin & $\begin{array}{l}\text { Artificial (protein, adenovirus as a carrier for the SARS CoV2 } \\
\text { RBD, attenuated virus, inactivated virus, RNA, DNA) }\end{array}$ & $\begin{array}{l}\text { Natural (concentrated commensal } \\
\text { bacteria and fungi from the colon) }\end{array}$ & {$[7,8,11,12]$} \\
\hline Availability & For about $30 \%$ of the world population & For all & {$[13,14]$} \\
\hline Side Effects & $\begin{array}{l}\text { Transverse Myelitis, Allergic reactions, Pain and Erythema at } \\
\text { the injection site, Fatigue and Headache }\end{array}$ & $\begin{array}{l}\text { Abdominal cramping, Nausea, Soft } \\
\text { stools, Flatulence }\end{array}$ & {$[4-6,15]$} \\
\hline Price & 3-37 EUR per dose & From 20 cents per capsule (tablet) & {$[16,14]$} \\
\hline Infectiveness & A vaccinated person may spread the COVID19 & $\begin{array}{l}\text { A person under probiotic protection } \\
\text { probably may not spread the } \\
\text { COVID19 }\end{array}$ & {$[7,17]$} \\
\hline Contraindications & $\begin{array}{c}\text { Age under 18, Pregnancy, Transplantations, Autoimmune } \\
\text { Diseases, Acute Infection }\end{array}$ & Severe immunological deficiencies & {$[7,18]$} \\
\hline Treatment of the COVID19 & No & Yes & {$[9,10]$} \\
\hline Aluminium Adjuvants & $\begin{array}{l}\text { Yes (Recombinant Protein-based Vaccine and Inactivated Virus } \\
\text { Vaccines) }\end{array}$ & No & {$[19,20]$} \\
\hline Storage & Low and very low temperatures & Room temperature & {$[7,17]$} \\
\hline
\end{tabular}

\section{Discussion}

\section{Origin}

The current anti-COVID19 vaccines under development are based on ten different artificial platforms:

1) Recombinant spike-protein-based vaccines;

2) Recombinant receptor-binding-domain vaccines;

3) Live attenuated vaccines;

4) Inactivated vaccines;

5) Virus-like particles based vaccines;

6) Replication-incompetent vector vaccines;

7) Replication-competent vector vaccines;

8) Inactivated virus vector vaccines;

9) DNA vaccines and

10) RNA vaccines [7].

On the other hand, probiotics are natural biological product, with live microorganisms (Lactobacillus sp., Bifidobacteria and Saccharomyces) that when administered in adequate amounts confer a health benefit on the host [12].

\section{Availability}

It has been assessed that the majority of the world population will be vaccinated against COVID19 until the end of 2021 [13]. On the other hand, probiotics are available immediately to the whole world population because they are over-the-counter drugs [14].

\section{Side Effects}

According to the available published results of the phase 3 for three approved vaccines are: one non-lethal case of transverse myelitis, allergic reactions, mild-to-moderate pain and erythema at the injection site, fatigue, and headache [4-6]. Concerning probiotics, the rare side effect are gastrointestinal (abdominal cramping, nausea, soft stools and flatulence) [15].

\section{Price}

The anti-COVID19 vaccine price per dose varies from 3-37 USD [16], while the probiotic price depends on the producer and the content and starts from 20 cents per capsule (tablet) [14].

\section{Application}

All 230 anti-COVID19 vaccines that are under development are applied in an invasive artificial way - intramuscularly, except for three of them that are applied in a natural way, with an intranasal spray [7]. All probiotics are applied in a natural way - per os [17].

\section{Infectiveness}

After an artificial immunization with an intramuscular vaccine, the human body lacks local immunity. Therefore, a vaccinated person against COVID19 may spread the disease. The sterilizing immunity is achieved only after intranasal vaccination, due to both secretory IgA and systemic IgG antibodies [7]. On the other hand a person protected with probiotics may be infected in a natural way and obtain both local and systemic immunity [17].

\section{Contraindications}

As the phase 3 trials of the approved anti-COVID19 vaccines have not encompassed children and pregnant women, autoimmune diseases, transplantations and acute infections, these are current contraindications for vaccination [7]. On the other hand, there are no contraindications for the application of probiotics, except for the severe immunological deficiencies [17]. 


\section{Treatment of COVID19}

A current COVID19 infection is a contraindication for antiCOVID vaccination. However, there are reports of a successful treatment of COVID19 with probiotics [9].

\section{Aluminium Adjuvants}

Aluminium adjuvants (Aluminium hydroxide) are being used in inactivated vaccines and recombinant protein vaccines against COVID19 [18]. Aluminium adjuvants have raised concerns related to long term side-effect of aluminium containing vaccines. Caution is needed concerning aluminium in the body as it is neurotoxic. Significantly raised concentrations of aluminium have been found in the brain of donors who had suffered from autism, Alzheimers disease and multiple sclerosis, compared to donors with no neurodegenerative diseases $[19,20]$. On the other hand, there are no aluminium adjuvants in probiotic preparations.

\section{Storage}

Anti-COVID19 vaccines are stored at low and very low temperatures, while probiotics are stored at room temperatures $[7,17]$.

\section{Conclusion}

Although vaccination is a dominating anti-COVID19 strategy, a comparative analysis of the key features of the vaccines $v S$. probiotics shows some important advantages of probiotics. Near future will show whether vaccination will be successful in fighting the COVID19 pandemic. If yes, that would be one more victory of the medical science. If not, probiotics will come into focus.

\section{Conflict of Interest}

The author declares no conflict of interest.

\section{Funding}

This work has received no funding.

\section{References}

1. Liu J, Liu S (2020) The management of coronavirus disease 2019 (COVID-19) J Med Virol 92(9): 1484-1490.

2. (2020) COVID19 - Coronavirus Pandemic.

\section{ISSN: 2574-1241}

DOI: 10.26717/BJSTR.2021.34.005487

Goran Belojevic. Biomed J Sci \& Tech Res

(C) This work is licensed under Creative

Submission Link: https://biomedres.us/submit-manuscript.php
3. Belojevic G (2020) COVID-19 and Spanish Flu Pandemics - Similarities and Differences. J Pharmacol Pharmaceutical Res 3(3): 1-3.

4. Voysey M, Clemens SAC, Madhi SA, Weckx LY, Folegatti PM, et al. (2020) Safety and efficacy of the ChAdOx1 nCoV-19 vaccine (AZD1222) against SARS-CoV-2: an interim analysis of four randomised controlled trials in Brazil, South Africa, and the UK. Lancet 397(10269): 99-111.

5. Polack FP , Thomas SJ , Kitchin N, Absalon J, Gurtman A, et al. (2020) Safety and Efficacy of the BNT162b2 mRNA COVID-19 Vaccine. N Engl J Med 383(27): 2603-2615.

6. Baden LR, Sahly HM, Essink B, Kotloff K, Frey S, et al. (2021) Efficacy and safety of the mRNA-1273 SARS-CoV-2 Vaccine. N Engl J Med 384: 403-416.

7. Krammer F (2020) SARS-CoV-2 vaccines in development. Nature 586(7830): 516-527.

8. Belojevic G, Prasher D (2019) Music of microbiota against SARS CoV-2. Noise Health 21(100): 97

9. Belojevic G (2020) Microbiota Against SARS CoV-2: Case Reports and a Model for Stopping the COVID-19 Pandemic. J Clin Med Case Reports.

10. Belojevic G (2020) The COVID19 pandemic can be stopped with probiotics. Biomed J Sci Tech Res 33(2): 25611-25612.

11. Bottari B, Castellone V, Neviani E (2020) Probiotics and COVID-19. Int J Food Sci Nutr 12: 1-7.

12. Hill C, Guarner F, Reid G, Gibson GR, Merenstein DJ, et al. (2014) Expert consensus document. The International Scientific Association for Probiotics and Prebiotics consensus statement on the scope and appropriate use of the term probiotic. Nat Rev Gastroenterol Hepatol 11(8): 506-514.

13. (2021) Goldman Sachs. The Road Ahead for COVID-19 Vaccines.

14. Amazon. Probiotic Nutritional Supplements.

15. Shira D, Snydman DR (2015) Risk and safety of probiotics. Clin Infect Dis 60(Suppl 2): S129-134.

16. (2020) Healthline. How Much Will It Cost to Get a COVID-19 Vaccine?.

17. Sanders ME (2015) Probiotics in 2015: Their Scope and Use. J Clin Gastroenterol 49 Suppl 1: S2-6.

18. Baud D, Agri VD, Gibson GR, Reid G and Giannoni E (2020) Using Probiotics to Flatten the Curve of Coronavirus Disease COVID-2019 Pandemic. Front Public Health 8: 186.

19. Hotez PJ, Corry DB, Strych U, Bottazzi ME (2020) COVID-19 vaccines: neutralizing antibodies and the alum advantage Nat Rev Immunol 20(7): 399-400.

20. Exley C, Clarkson E (2020) Aluminium in human brain tissue from donors without neurodegenerative disease: A comparison with Alzheimer's disease, multiple sclerosis and autism Sci Rep 10(1): 7770.

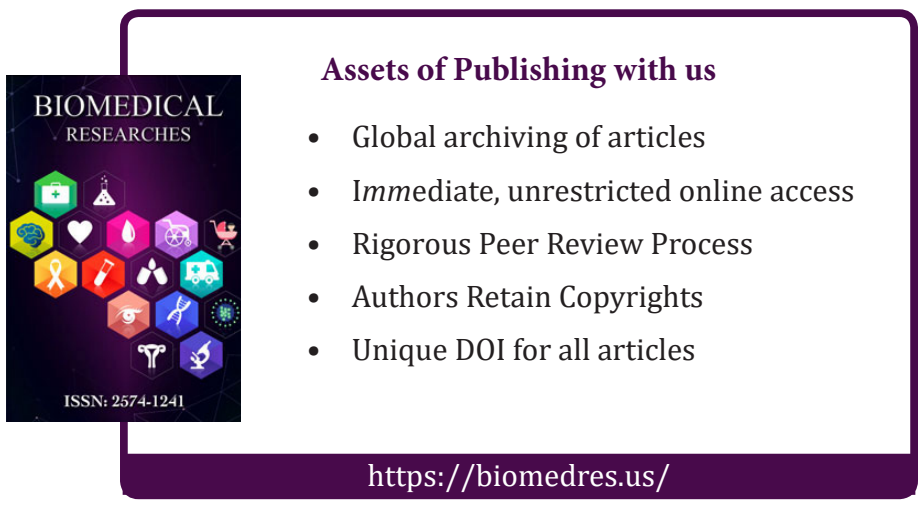

Copyright@ Goran Belojevic | Biomed J Sci \& Tech Res | BJSTR. MS.ID.005487. 